\title{
DYNAMIC VERSUS QUASI STATIC FRACTURE TOUGHNESS OF ADDITIVELY MANUFACTURED AISi10Mg ALLOY BY SELECTIVE LASER MELTING TECHNIQUE
}

\author{
E. Chakotay ${ }^{*}$, R. Carmi, I. Alon ${ }^{1}$, R. Shneck ${ }^{2}$, M. Pinkas ${ }^{1}$, A. \\ Stern'2,3, A. Bussiba
}
${ }^{1}$ Materials Department, Nuclear Research Center Negev, P.O.B. 9001, Beer Sheva, 8410900 Israel
${ }^{2}$ Department of Materials Engineering, Ben-Gurion University of the Negev, P.O.B. 653, Beer-Sheva, 8410501 Israel
${ }^{3}$ School of Mechanical Engineering, Afeka Academic College of Engineering, Tel Aviv, 69107, Israel
*Corresponding author's e-mail address: chakotay@post.bgu.ac.il

\begin{abstract}
In today's additive manufacturing sector, one of the most popular areas is selective laser melting (SLM) due to its capability of producing geometrically complex metal parts directly from CAD model in a few short steps. Many studies have been reported on static mechanical properties of SLM components; however, dynamic properties of SLM components of different materials have not been thoroughly investigated. Only few papers have been published on the dynamic mechanical behavior, especially in the crack resistance of selective laser melted AlSi1OMg alloy. In the present study, the effect of loading rate, dynamic versus quasi static, on the fracture toughness of the as-built alloy ( $X$ and $Z$ orientations) has been investigated. The experimental results revealed the inherently anisotropic behavior for loading rates where the Z orientation exhibited lower toughness compared to the $x$ orientation. The dynamic loading by impact, resulted in a significant decrease of the toughness values up to about $50 \%$ compared to the quasi-static loading. This mechanical response was attributed to the increase in the yield stress which alters the state stress at the crack tip from the planestress to some extent of the mix-mode plane stress/strain.
\end{abstract}

KEYWORDS: AISi10Mg alloy, AM-SLM powder-bed system, fatigue initiation fracture toughness, quasi static, dynamic properties, impact loading.

\section{ACKNOWLEDGEMENTS}

The authors would like to thank Sharon Tuvia (1982), Ltd. for the valuable contributions and fruitful discussions, as well as Mrs. H. Didi and Dr. A. Varseblat of the Department of Materials Engineering, Ben-Gurion University of the Negev for their valuable assistance. Finally, the authors thank the Materials Engineering group from Tel Aviv University for using the impact testing machine.

\section{REFERENCES}

[1] Rosenthal I., Shneck R., Stern A., Heat treatment effect on the mechanical properties and fracture mechanism in AlSi10Mg fabricated by additive manufacturing selective laser melting process, Materials Science and Engineering: A, 729, 2018, pp. 310-322.

[2] Baxter C., Cyr E., Odeshi A., Mohammadi M., Constitutive models for the dynamic behavior of direct metal laser sintered AlSi10Mg_200C under high strain rate shock loading, Materials Science and Engineering: A, 731, 2018, pp. 296-308.

[3] Rosenthal I., Stern A., Frage N., Strain rate sensitivity and fracture mechanism of AlSilOMg parts produced by selective laser melting, Materials Science and Engineering: A, 682, 2017, pp. 509-517.

[4] Uzan N. E., Ramati S., Shneck R., Frage N., Yeheskel O., On the effect of shot-peening on fatigue resistance of AlSi10Mg specimens fabricated by additive manufacturing using selective laser melting (AM-SLM), Additive Manufacturing, 21, 2018, pp. 458-464.

[5] Uzan N. E., Shneck R., Yeheskel O., Frage N., Fatigue of AlSi10Mg specimens fabricated by additive manufacturing selective laser melting (AM-SLM), Materials Science and Engineering: A, 704, 2017, pp. 229-237.

[6] Zaretsky E., Stern A., Frage N., Dynamic response of AlSilOMg alloy fabricated by selective laser melting, Materials Science and Engineering: A, 688, 2017, pp. 364-370.

[7] Rosenthal I., Tiferet E., Ganor M., Stern A., Selective Laser Melting Additive Manufacturing: AlSi10Mg Powder Characterization, Welding Equipment and Technology, 25, 2015, pp. 35-40.

[8] Hadadzadeh A., Amirkhiz B.S., Li J., Odeshi A., Mohammadi M., Deformation mechanism during dynamic loading of an additively manufactured AlSi10Mg_200C, Materials Science and Engineering: A, 722, 2018, pp. 263-268. 
[9] Brandão A. D., Gumpinger J., Gschweitl M., Seyfert C., Hofbauer P., Ghidini T., Fatigue Properties of Additively Manufactured AlSil0Mg-Surface Treatment Effect, Procedia Structural Integrity, 7, 2017, pp. 58-66.

[10] Stern A., Rosenthal Y., Berger A., Ashkenazi D., Additive Manufacturing from Fundamental to Applications, Welding Equipment and Technology, 28, 2018, pp. 51-58.

[11] Kempena K., Thijsb L., Van Humbeeckb J., Krutha J.-P., Mechanical properties of AlSi10Mg produced by Selective Laser Melting, Physics Procedia, 39, 2012, pp. 439-446.

[12] Asgari H., Odeshi A., Hosseinkhani K., Mohammadi M., On dynamic mechanical behavior of additively manufactured AlSilOMg_200C, Materials Letters, 211, 2018, pp. 187-190.

[13] Nurel B., Nahmany M., Frage F., Stern A. Sadot O., Split Hopkinson pressure bar tests for investigating dynamic properties of additively manufactured AlSi10Mg alloy by Selective Laser Melting, Additive Manufacturing, 22, 2018, pp. 823-833.

[14] Noriko R., Wei W., Khamis E., Moataz M. A., Selective Laser Melting of AlSil0Mg alloy: Process optimization and Mechanical Properties, Development. Materials and Design, 65, 2015, pp. 417-424.

[15]*** ASTM E399 - 90 (Reapproved 1997), Standard Test Method for Plane-Strain Fracture Toughness of Metallic Materials, American Society for Testing and Materials 100 Barr Harbor Dr., West Conshohocken, PA 19428.

[16]*** ASTM E24.03.03 (Reapproved 2003), Proposed standard method of test for instrumented impact testing of pre-cracked charpyspecimens of metallic materials, American Society for Testing and Materials 100 Barr Harbor Dr., West Conshohocken, PA 19428.

[17]Arpan D., Soumitra T., Geometry of dimples and its correlation with mechanical properties in austenitic stainless steel, Scripta Materialia, 59, 2008, pp. 1014-1017.

[18]Wang W., Ma Y., Yang M., Jiang P., Yuan F., Wu X., Strain Rate Effect on Tensile Behavior for High Specific Strength Steel: From Quasi-Static to Intermediate Strain Rates, Metals, 8, 11, 2018, pp. 1-14. 